Journal of Neurology, Neurosurgery, and Psychiatry 1984;47:73-76

Short report

\title{
Isolated benign cerebral vasculitis or migrainous
} vasospasm?

\author{
M SERDARU,${ }^{*}$ J CHIRAS,$\dagger$ M CUJAS, $\ddagger$ F LHERMITTE \\ From the Clinique de Neurologie et Neuropsychologie, ${ }^{*}$ Service de Neuroradiologie, $\dagger$ and Laboratoire \\ d'histologie et d'embryologie, $\ddagger$ Hôpital de la Salpêtrière, Paris, France
}

SUMMARY A 39-year-old woman experienced severe headache, epilepsy and rapidly progressive aphasia and hemianopia. Carotid angiograms displayed segmentary narrowing of intracranial arteries as previously described in benign cerebral vasculitis. Her superficial temporal artery was also involved, allowing a biopsy of the abnormal part of the vessel. Microscopical study of this artery was normal. A second carotid angiogram, 14 days later, showed normal intracranial arteries. These findings suggest arterial spasm rather than distal arteritis.

Segmental narrowing of intracranial arteries revealed by angiography, is usually the main evidence for the diagnosis of intracranial arteritis, or of vasospasm. Intracranial arteritis has been described in diseases such as syphilis and tuberculosis. ${ }^{1}$ Pathological studies have confirmed the radiological diagnosis. The same segmentary narrowing, occurring without any associated disease has been described as "intracranial arteritis of spontaneous benign outcome". ${ }^{2-4}$ This diagnosis has not yet been pathologically confirmed.

We have observed a case similar in its clinical evolution and angiographic features to the so-called intracranial arteritis of spontaneous benign outcome. However, a normal biopsy of a radiologically narrowed segment led us to conclude that our patient had arterial vasospasm rather than vasculitis.

\section{Case report}

A 39-year-old woman with a known drinking habit had a past history of headaches with nausea before the age of 20 years. No headaches or oral contraceptive use were noted in her recent history.

On 11 April she suddenly experienced severe pulsatile headache and nausea, partially relieved by aspirin. On 18

Address for reprint requests: Dr M Serdaru, Hôpital de la Salpêtrière, 47 Blvd de l'Hôpital, 75634 Paris Cedex 13, France.

Received 27 December 1982 and in revised form 7 May 1983 Accepted 5 July 1983
April at $10 \mathrm{pm}$, still complaining of headache, she had a seizure while watching television. She was found to be confused and on admission to hospital at 1 am was drowsy. She did not understand simple orders and her answers were confused, both because of their irrelevant character and because of paraphasias. Few spontaneous or elicited movements were observed in the right limbs, and there was a right sided homonymous hemianopia. Blood pressure was $130-800 \mathrm{mmHg}$, body temperature $38^{\circ} \mathrm{C}$. Routine laboratory examinations were within normal limits: ESR $15 \mathrm{~mm} / 1 \mathrm{hr}, 38 \mathrm{~mm} / 2 \mathrm{hr}$, serum protein electrophoresis was normal, antinuclear antibody test negative, Addis count normal, blood ethanol $0.5 \mathrm{~g} / \mathrm{l}$. Her CSF contained $0.43 \mathrm{mg} / \mathrm{ml}$ proteins, 7 erythrocytes and 6 lymphocytes $\mathrm{mm}^{3}$. The EEG showed slow waves in the left parietooccipital area. On 22 April, bilateral carotidography was performed by femoral route under uneventful fentanyl anaesthesia. The common, internal and external carotid arteries had a normal lumen on both sides. The intracranial carotid branchial had several segmental narrowings (fig 1) more prominent on the left side and in the middle and anterior cerebral arteries. The superficial temporal artery displayed the same abnormalities.

A diagnosis of distal arteritis of the central nervous system was suspected. The next day (23 April) the narrowed segment of the left superficial temporal artery was removed under local anaesthesia (G Robert, Neurosurgical Dept, Prof. Pertuiset). From 19 April, the patient was given intramuscular thiamin $1 \mathrm{~g}$ daily. On 22 April she was normally alert, the aphasia and right hemianopia had improved. By 25 April only mild sensory aphasia was found on neurologic examination. From 5 to 7 May she received intravenous magnesium sulphate, $15 \%$, $40 \mathrm{ml}$ daily. On 7 May, after receiving $40 \mathrm{ml}$ of magnesium 

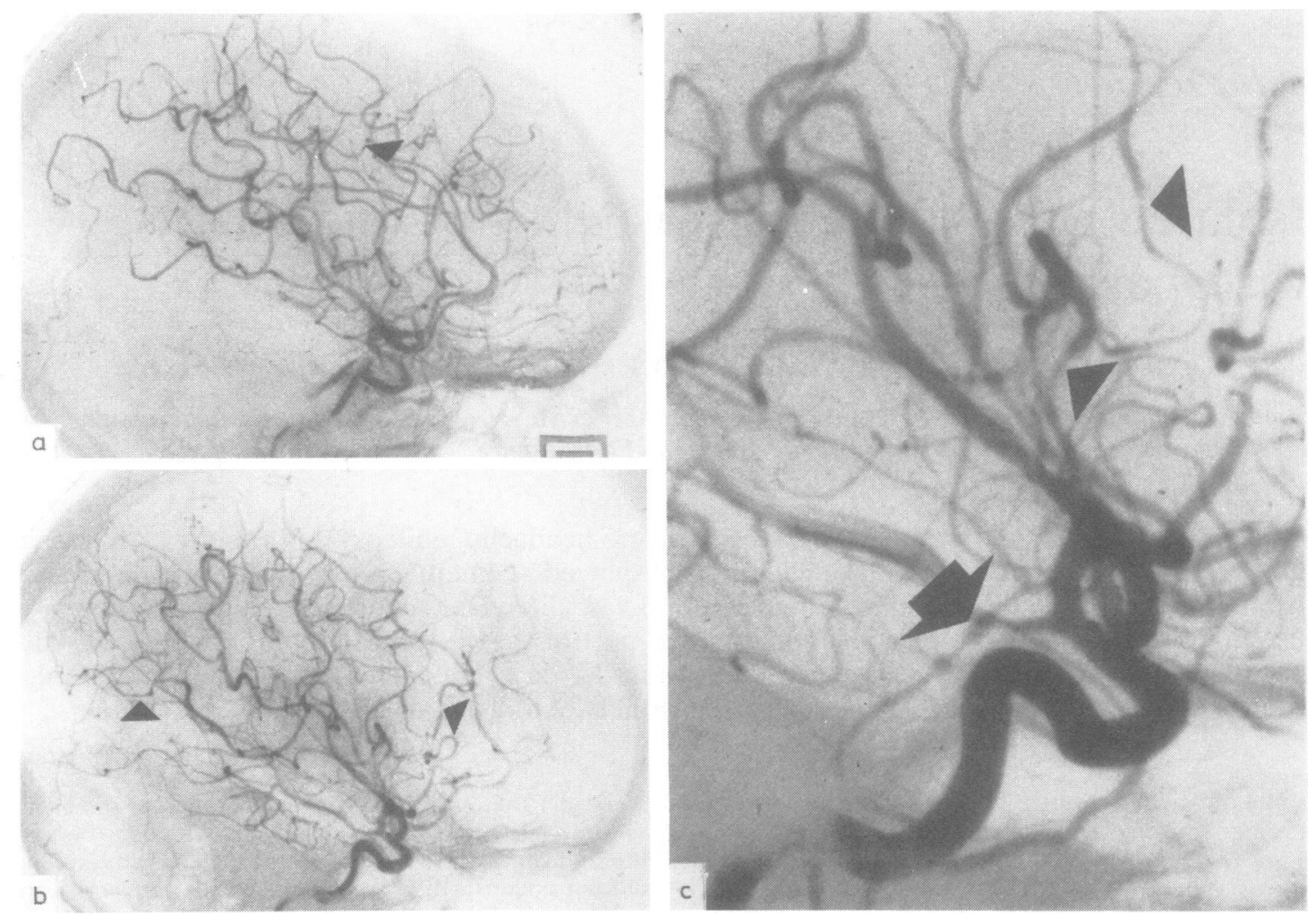

Fig 1a, b, c Selective arteriography of common carotid arteries (right 1a, left 1b): segmental narrowings of cortical arteries. Ic, detail of the left side. Arrows indicate the segmental irregularities of the left middle cerebral artery, and of the left superficial temporal artery.

sulphate from 7 to $10 \mathrm{am}$, a second arteriogram was performed, under the same conditions as the original. The abnormalities had disappeared (fig 2). Selective catheterisation of the left external carotid artery confirmed the removal of the superficial temporal artery.

The biopsy was embedded in paraffin, serially sectioned and stained with haematein-phloxin-safran, trichrome Masson, and succine-paraldehyde. No abnormalities were seen, in spite of careful search for inflammatory or other pathological features.

\section{Discussion}

The main point of our report is that angiographically-demonstrated narrowing of the superficial temporal artery may be normal histologically. The biopsy technique was the same as that used to obtain diseased arterial segments in Horton's arteritis, identified by angiography. Angiography after biopsy confirmed that the correct artery had been biopsied. Several sections studied microscopically, did not display abnormality.

Isolated benign cerebral vasculitis or benign distal intracranial arteritis has been the diagnosis suggested in several reports of patients with common clinical features, whose angiograms displayed segmental narrowing of their intracranial arteries. The disease occurs in young people, more often women. Headache and nausea are the initial symptoms. Focal deficit is often found. Subarachnoid haemorrhage is ruled out by CSF examination and CT scan. Angiographic abnormalities lead to this diagnosis. The disease has a benign course: the symptoms spontaneously regress in 7 to 10 days; the angiographic abnormalities disappear in 6 to 8 weeks. Snyder and McClelland ${ }^{2}$ have reported one case with a similar history. After ruling out several know inflammatory arteriopathies, they suggested that benign vasculitis 


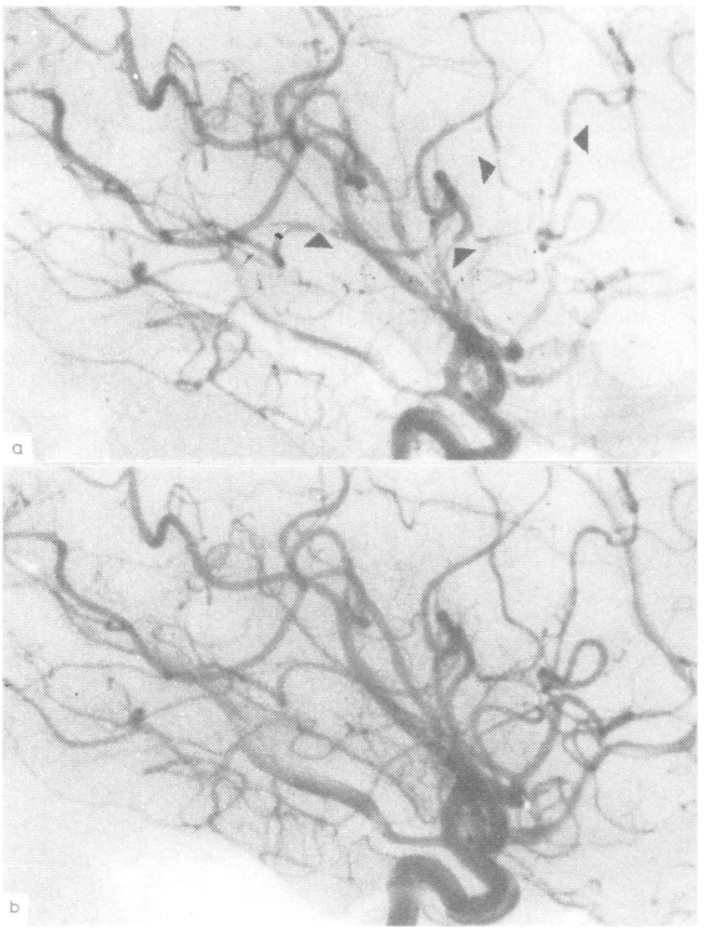

Fig 2 (a) first left carotid angiogram, displaying segmental abnormalities. (b) left carotid angiogram, 3 weeks later showing normal arteries without segmental narrowing.

could be a new, distinct entity. Rascol et $a l^{3}$ have singled out a new group of cerebrovascular accidents of pregnancy and postpartum, called "cerebral postpartum angiopathy". The four patients included in this group differed from our patient in very few respects. Only the occurrence in the postpartum period was a feature in common ( 5 days, 3 hours, 1 month, 3 days); two had very abnormal CSF $(2 \cdot 2 \mathrm{~g} / 1$ proteins, 1780 erythrocytes $/ \mathrm{mm}^{3}$ respectively). None had arterial hypertension or renal disorder. Some distal arterial occlusions were seen. Rousseaux et $a l^{4}$ have reported similar patients and suggested the diagnosis of "benign distal intracranial arteritis". We have not found a published histological report, as the disease is benign and the angiographical abnormalities usually involve only the intracranial arteries which does not allow biopsy.

Arterial spasm secondary to subarachnoid haemorrhage or to head trauma produces the same segmentary narrowing. Primary, "spontaneous" vasospasm occurs in migraine, but when angiograms have been performed during, or after a migraine attack, such appearances have not been seen. Very few reports describe the cerebral arteriographic

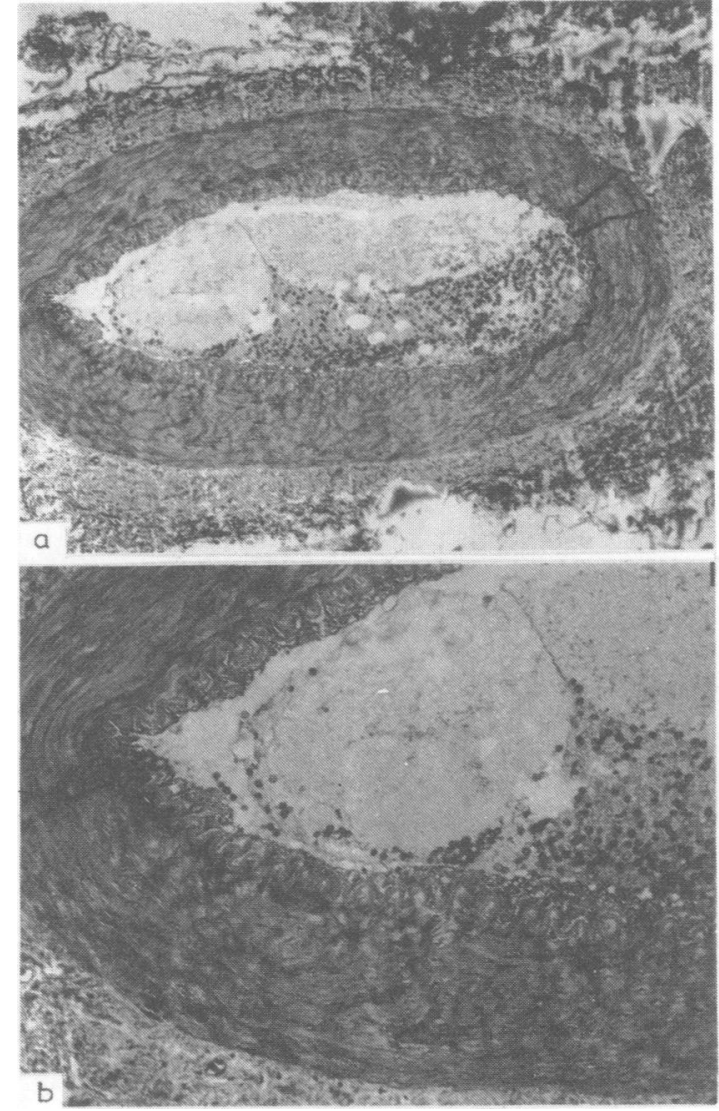

Fig 3a, b Left superficial temporal artery biopsy. (Masson's trichrome. $3 a \times 10,3 b \times 40$ )

changes in patients with various types of migraine but all of them describe narrowing of the internal carotid artery either in its extradural, ${ }^{56}$ or intracavernous part. $^{78}$ Intracranial segmentary narrowing has not been described previously in migraine. However, it is clear from our findings that arterial narrowing usually attributed to arteritis may be due to migraine.

The possible action of magnesium sulphate on vasospasm of intracranial arteries should be considered. Altura ${ }^{9}$ has mentioned the possible action of magnesium in experimental vasospasm in canine cerebral arteries. Magnesium sulphate was tried in our patient, as spasm was the suspected diagnosis. The radiological resolution of the segmental narrowing fell short of the predicted 6 to 8 weeks previously reported. The short duration of her angiographical abnormalities (19 days) is perhaps related to the effect of magnesium sulphate. 


\section{References}

' Liebeskind A, Cohen S, Anderson R, Schechter MM, Zingesser LH. Unusual segmental cerebrovascular changes. Radiology 1973;106:119-22.

${ }^{2}$ Snyder BD, McClelland RR. Isolated benign cerebral vasculitis. Arch Neurol 1978;35:612-14.

${ }^{3}$ Rascol A, Guiraud B, Manelfe C, Clanet M. Accidents vasculaires cérébraux de la grosesse et du post partum. In: Cerebrovascular Diseases, II Conference de la Salpêtrière. Paris: JB Baillière, 1980:85-127.

${ }^{4}$ Rousseaux P, Guyot JF. Une nouvelle variété d'artériopathie cérébrale. A propos de 3 cas. Neurochirurgie 1981;27:141.

${ }^{5}$ Dukes MT, Vieth RG. Cerebral arteriography during migraine and headache. Neurology (Minneap) 1964;14:636-9.

- Ekbom K, Greitz T. Carotid angiography in cluster headache. Acta Radiol [Diag] 1970;10:177-86.

${ }^{7}$ Bickerstaff ER. Ophthalmoplegic migraine. Rev Neurol (Paris) 1964;110:582-8.

${ }^{8}$ Walsh JP, O'Doherty DS. A possible explanation of the mechanism of ophthalmoplegic migraine. Neurology (Minneap) 1960;10:1079-84.

${ }^{9}$ Altura BT, Altura BM. Magnesium deficiency induces cerebral arterial spasm. Stroke 1981;118:12. 